\title{
أهمية تطبيق التعليم الالكتروني في التعليم العالي في العراق
}

\section{م.م رنا حكمـت عباس

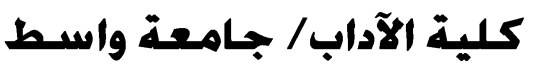

الخنلاصنة :

6،تضمن هذا البحث وصف أهمية تطبيق التعليم الاكتروني في التعليم العالي في العراق ومدى الاستفادة من تطبيقه في مؤسسـات

التعليم العالي ضمن مؤشرات توصل اليها البحث وكيفية توظيفها للحكم على جودة مؤسسـات التعليم بهـف تحسينهِهِ وتجويدهِ وتطويرهِ ، و و

ضرورة وضع هذِِ المعايير موضع التطبيق الفعلي للاستفادة منها في تقويم جودة المؤسسات التعليمية العراقية مستقبلاً “،

Abstract:

Include this research describe the importance of the application of e-learning in" higher education in Iraq and how to take advantage of its application in the institutions of higher education in the institutions within the indicators reached by the research and how to employ them to judge the quality of education institutions in order to improve the intonation and development, and the need to develop these standards into the actual application to take advantage of them in evaluating the quality of educational institutions in the future of Iraq."

\section{المقدمة}

“يتميز هذا العصر بالتغير ات السريعة الناجمة عن التقدم العلمي و التكنولوجي وتقنية المعلومـات ، لذا أصبح من الضروري على النظام التربوي مواكبة هذه التغيرات لمواجهة المشكلات التي قد تنجم عنها مثل كثرة المعلومات وزيادة عدد المتعلمين ونقص المعلمين وبعد المسافات. وقد أدت هذه التغيرات إلى ظهور أنماط وطر ائق عديدة للتعليم و التعلم” ، “خاصة مع ظهور الثورة التكنولوجية في تقنية المعلومات ، والتي جعلت من العالم قرية صغيرة ممـا أدى إلى زيـادة الحاجـة إلى تبـادل الخبرات مـع الآخرين ، وحاجـة المتعلم لبيئات غنيـة متعددة المصادر للبحث و التطوير الذاتي”، “فظهر الكثير من الأسـاليب والطرائق و الوسـائل الجديدة في التعليم و التعلم ، ومن ذلك ظهور التعلم الإلكتروني ، و الذي يعرف بأنه طريقة للتعلم باستخدام آليات الاتصـال الحديثة من حاسوب وشبكاته ووسـائطه المتعددة من صسوت وصسورة ورسومات و آليـات بحث ومكتبـات إلكترونيـة ،

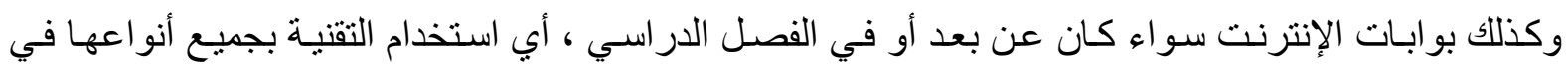

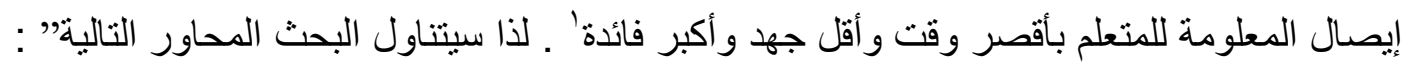

اولاً: مشـكلة البحث وأمميته وأمدافه ومصطاتحساته . ثانياً :. ،“تأريخ التعليم العالي ومراحل تطور التعليم الالكتروني” . ثالثاً :. “بعض الحقائق عن التعليم الالكتروني” . رابعاً :"علاقة التعليم الاكتروني بالمصطلحات الاخرى” . خامساً : “،أهداف التعليم الالكتروني و أنماطه ، فو ائده ، مميز اته ومزاياه” . سادساً: “،الاستتناجات و التوصيات و المقترحات”. او لاً : مشكلة البحث وأهميته و أهدافه البحث . 


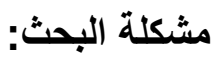

“يمـر التعليم العـالي في العـراق بأزمـة حـادة تشـمل كافة مقوماتـهـه مـن الأستاذ والطالب إلى المنــاهج الدراسية و النظـام التعليمسي ووسـائله و المستلزمات الدر اسية إلى الأنظمـة الإداريـة و غير ذلك وفي هذا البحث سنركز على وسيلة فاعلة وحديثة يمكن أن تساعد على تطوير التعليم العـالي وتجعله يتتـاغم مـع مـا يثـهـه العـالم

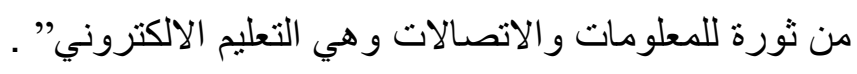

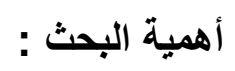

“بعيش العالم في الفترة الأخيرة ثورة علمية و تكنولوجية كبيرة ، كان لها تأثير كبير على جميع جو انب الحياة ، و أصبح التعليم مطالباً بالبحث عن أسـاليب و نمـاذج تعليمية جديدة لمواجهة العديد من لن التحديات على المستوى العالمي منها”: “'زيادة الطلب على التعليم مع نقص عدد المؤسسـات التعليميـة ، و زيـادة الكم المعلوماتي في جميع فروع المعرفة ـ فظهر نموذج التعليم ليساعد المتعلم على التعلم في المكان الذي يريده و في الوقت E-Learning الإلكتروني الذي يفضله". أهداف البحث “بيان أهمية تطبيق التعليم الالكتروني في التعليم العالي في العراق .

تتبع أهمية البحث من أهمية التعلم الإلكثروني بوصفه تقنية حديثة في العملية التعليميـة التعلميـة تساهم في حل الكثير من المشكلات التعليميـة مثل الانفجار المعرفي وثورة المعلومـات ومشكلة عدم مر اعاة

الفروف الفردية بين المتعلمين وازدحام القاعات الدر اسية بالطلبة ونقص عدد المعلمين المؤهلين و المدربين”. “ ضرورة توفير البنية التحتيه لهذا النوع من التعليم و التي تتمثل في إعداد الكوادر البشرية

المدربة وكذلك توفير خطوط الإتصالات المطلوبة التي تساعد على نقل هذا التعليم من مكان لآخر”.

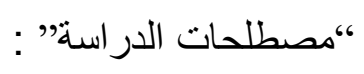

\section{" e-learning"}

“نمط تعليمي تفاعلي يرتكز على المتعلم ، ويعتمد على تصميم بيئة التعلم بشكل ييسر التعليم ، باستخدام

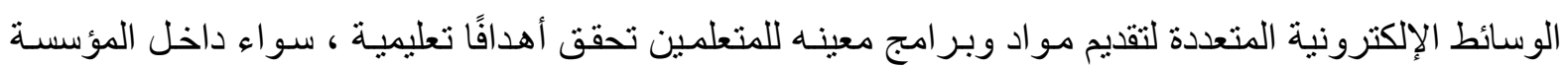

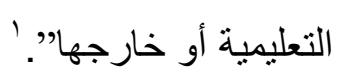

“،التعليم الالكترونسي أو الافتراضـي هـو ذلـك النـوع مـن التعليم الـذي يعتمد على استخدام الوسـائط

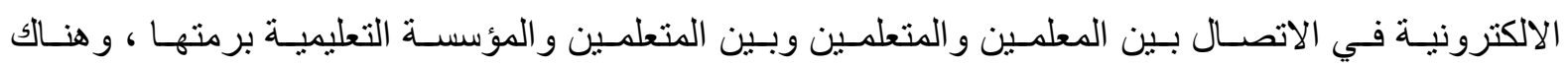
مصطلحات كثيرة تستخدم و Web Based Education و Online Education: بالتبادل مع هذا المصطلح منها"

“و غيرهـا مـن المصـطلحات .لكـن الأفضـل اسـتخدام مصـطلح التعلـيم Edectronic Education الالكتروني بدلا من مصطلح التعليم الافتراضي ، وذلك لأن هذا النوع من التعليم شبيه بـالتعليم المعتاد إلا أنـه 
يعتمد على الوسـائط الالكترونيـة ، فـالتعليم إذن حقيقيـا وليس افتر اضـيا كمـا يـل على ذللك مصسطلح التعليم الافتر اضـي ـ يقول دوبس وفليب : " إن المـتعلم إلكترونيـا هـو مـتعلم حقيقي لكنـه يـتعلم في بيئـة إلكترونيـة

r’(Dubois, and Phillipp)

“زذلك النوع من التعليم القائم على شبكة الحاسب وفيه تقوم المؤسسـة التعليميـة بتصميم موقع خـاص بها

ولمواد أو ، (World Web Wide) الآلي بر امج معينة لها ، ويتعلم المتعلم فيه عن طريق الحاسب الآلي وفيه

يتمكن من الحصول على التغذية الراجعة ، ويجب أن يتم وفق جداول زمنية محددة حسب البرنـامج التعليمي ، وبذللك نصل بالمتعلم إلى التمكن من ما يتعلمه. وتتعدد بر امج التعليم المقدمة من بر امج تعليميـة على مستويات

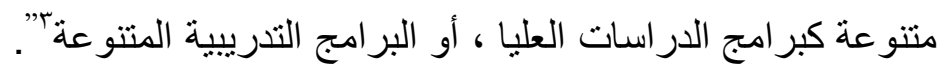

“بأنه : نظام تعليمي يستخدم تقنيات المعلومـات و شبكات الحاسوب في تدعيم و توسيع نطاق العملية التعليمية من خلال مجموعة من الوسائل منها : أجهزة الحاسوب ، الإنترنت ، البر امج الإلكترونية المعدة إما من

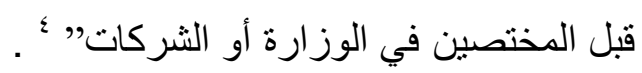

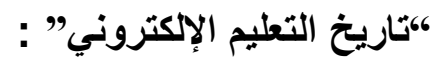

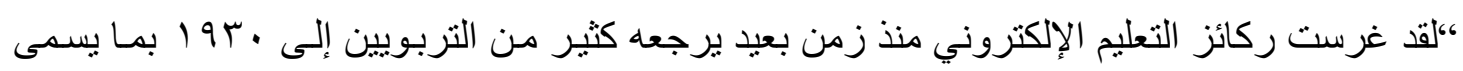

بالكتب المبرمجة والتي كان يستخدمها جنود الجيش الأمريكي كبر امج تعليمية (ليس للمعلم اي حضور فيها) ومنذ ذلك الحين و إلى اليوم وتللك الفكرة تدرس وتعدل ومن ثم تدرس وتعدل الى أن وصلت الى مـاوصلت إليه من ثمرة يجني ثمار ها الكثير من المتعلمين في تلك البلاد " . “و يقول د. غازي القصيبي أن هذا التعليم بدأ في شيكاغو وموسكو في مطلع الستينيات ، إلا أنه لم يولا ولادة حقيقية إلا مـع الجامعة المفتوحة في بريطانيا سنة

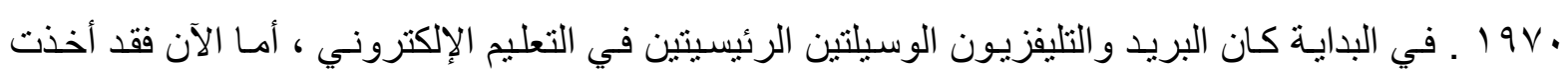

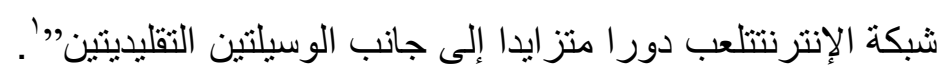

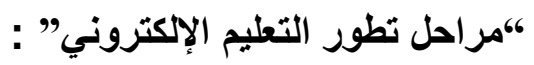

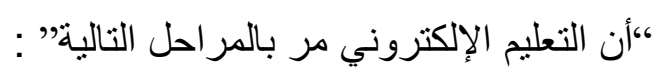

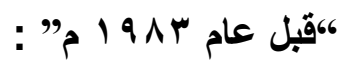

“عصر المدرس التقليدي ، حيث كان التعليم تقليدياً قبل انتشـار أجهزة الحاسبات بـالرغم من وجودهـا

لاى البعض ، وكان الاتصال بين المدرس و الطالب في قاعة الدرس حسب جدول در اسي محدد” .

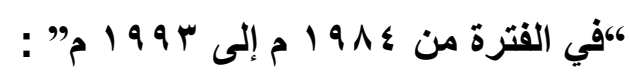

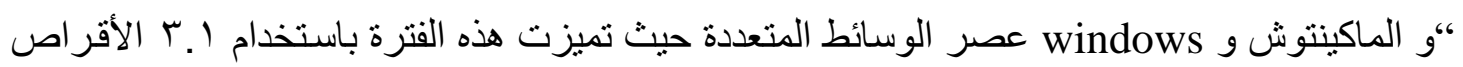
الممغنطة كأدوات رئيسية لتطوير التعليم” .

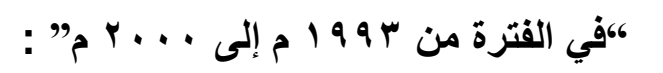

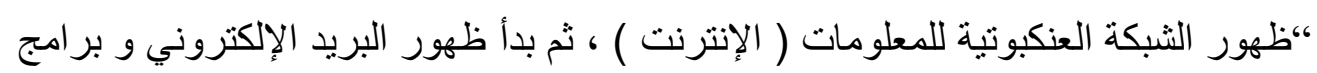




$$
\text { إلكترونية أكثر إنسيابية لعرض أفلام الفيديو” . }
$$

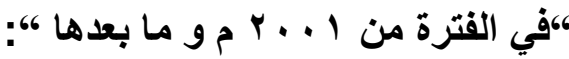

“،الجيل الثاني للثبكة العنكبوتية حيث أصبح تصميم المواقع على الث بكة أكثر تقدماً ذوخصائص أقوى بعى

من ناحية سر عة سريان و استقبال الملفات و المعلومات و البيانات” '.

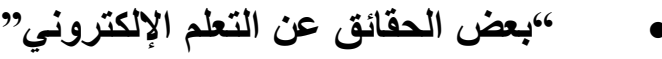

ــ ، “التعلم الإلكتروني يتضمن المعلومات و الاتصالات و التعليم و التدريب”.

r- ، التعليم الالكتروني ليس مجرد وسيلة للتنريب الالكتروني و أنما يستخدم لأغر اض أخرى كثيرة مثل أدارة المعرفة و إدارة الأداء و أقامة المكاتب الافتر اضية و غبر ها من الأنشطة”.

זـ “التعليم الالكتروني لا يعتمد فقط على التكنولوجيا و أنما على ثقافة المنظمة و القيادة و إدارة التغيير”. ـ ـ “لايمكن للتعلم الإلكتروني أن ينجح بدون التزام واقتناع الإدارة العليا والقائمين على التنفيذ والمتدربين” . هـ “يجب أن تتو افق استرايجيات التعليم الالكتروني مع الاستر اتيجيات العامـة للمنظمـة لكي تحقق الهدف منها فهي وسيلة وليس غاية كما انها ليست في كل الاحو ال بديلاً للتدريب التقليدي و إنما قد مكملة له'”.

\section{، ،علاقة التعليم الإلكتروني بالمصطلحات الأخرى" :}

“جاءت العديد من المصطلحات التي ترادف معنى التعليم الإلكترو ني ، مثل : التعلم الافتراضي لمزي

التعلم عن طريق الإنترنت (التعلم المبني على الواقع الافتراضي ) Learning Virtual التعلم

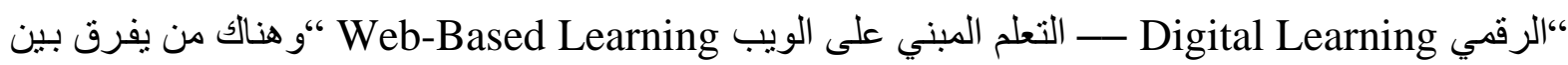
التعليم الإلكتروني Online Learning و التعلم الثبكات الإكتروني Network Learning “فالأول يتطلب جهداً يبـل لتحقيق أهداف العمليـة التعليميـة مـن قبـل المعلم و المتعلم ، أمسا الثاني فهي عمليـة فرديـة يقوم بها

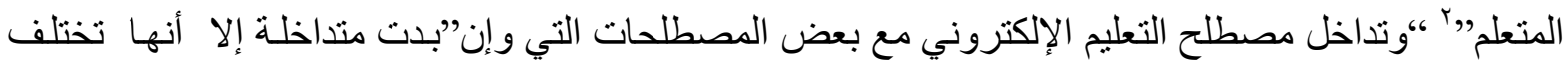

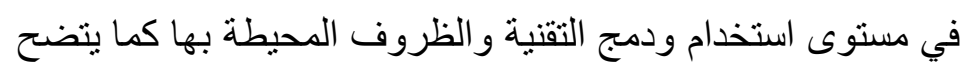

“من الثكل ( ( ) الذي يبين مستويات استخدام التكنولوجيا في أنماط التعليم”"
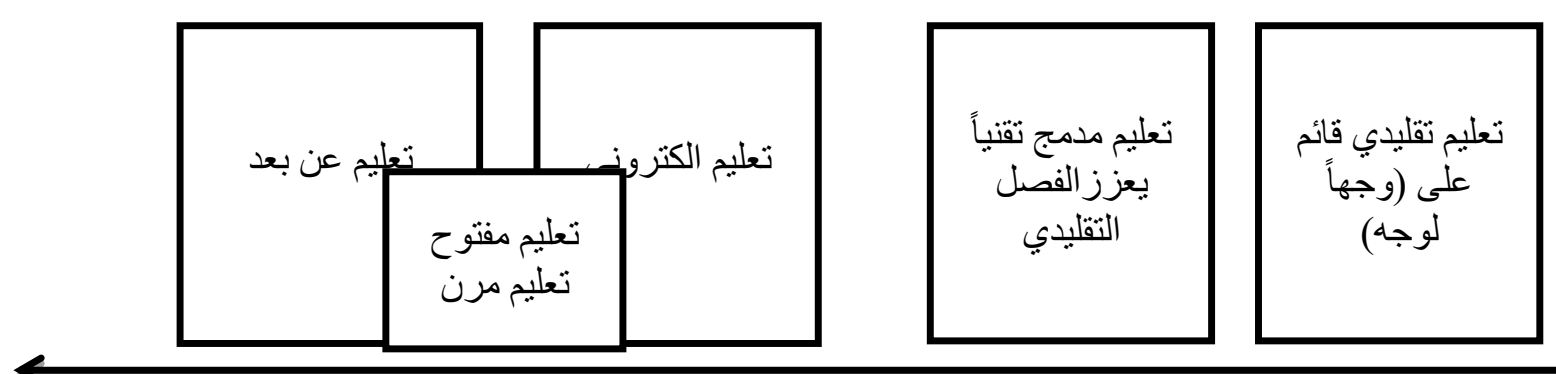

$66 \ddot{a}$ دعم بالتقني. غبـ تعلـ 
“ويمكن تعريف المصطلحات الواردة في الثكل ( () وتوضيح العلاقة بينها وبين التعليم الإلكتروني

Flexible learning" في القاعات الدراسية التقليديـة المعتمد على المحاضـرات و المو اد المطبوعـة ، وجعل التعليم متاحًا لطالب في أماكن و أوقات مختلفة وبتكاليف مخفضة كما يمكن اعتبار التعليم الإلكتروني أحد نماذج التعليم المرن”'. Blended Learning” يتم من خلاله استخدام وسائل اتصال مختلفة تتضمن الإلقاء المباثـر والتعلم الذاتي والتواصل عبر الإنترنت ، فهو يمزج بين التعليم الاعتيادي وبين استخدام التقنيات التعليمية المتنو عة ممـا يعطي الحريـة للمعلم في استخدام

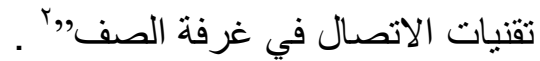

Open Learning" يفرضـها النظـام التقليدي على الطالب ، خاصـة فيمـا يتعلق بالانفتـاح في القبول ، ووسـائل التعليم ، ومسنتوى المناهج” ، “"، المسافات و المكان والزمان ، حيث يتمتع الطالب بحريـة غير محدودة في اختيار مـا يتناسب مـع

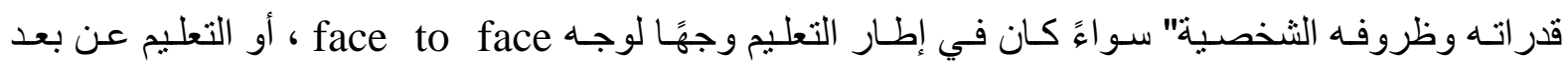
r'"distance learning Distance Learning" كانت تقليديـة (المطبوعـات ، و أنثرطة التسـيل ، و الر اديو، و التلفـاز) أو حديثة (الحاسب الآلكي وبرمجياتهـه ، وشـبكة الإنترنــت ، و القنـوات الفضـائية ، و الهـاتف الجـوال) حيـث يفصـل المعلـم و المـتعلم مسـاحات جغر افيـة واسعة؛" ، “ورغم التشابه الكبير بين التعليم الإلكتروني و التعليم عن بعد إلا أنه لا يمكن اعتبار هما الثـيء نفسـه

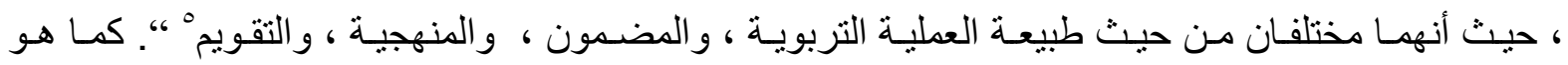

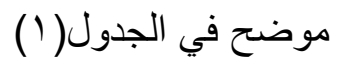

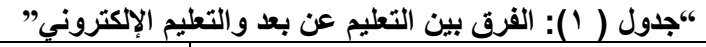

\begin{tabular}{|c|c|c|}
\hline التعليم الاكتروني & التعليم عن بعد & العنصر \\
\hline بخطوة. & 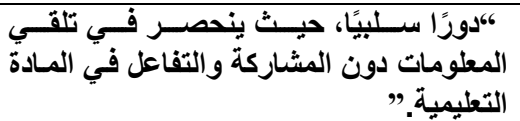 & ك“دور المتعلم” \\
\hline 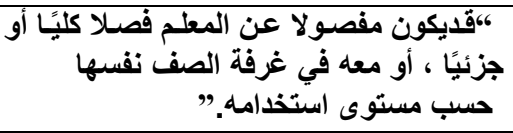 & “يجب أن يكون مفصولا عن المعلم كليا.” & “،مكان المتعلم “ \\
\hline 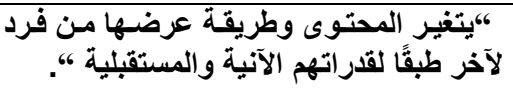 & 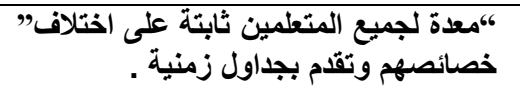 & 6،المادة التُليمية" \\
\hline 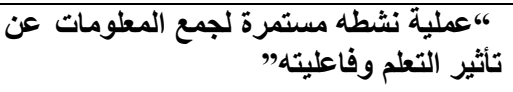 & ““تقويم انجازات الطالب في نهاية البرنامج”" & 6،|التقويم" \\
\hline
\end{tabular}

“ويهدف التعلم الإلكتروني إلى تحقيق أهداف عديدة منها” : 
1. “، إمكانيـة تعـويض الـقص في الكوادر الأكاديميـة و التدرييـة في بعض القطاعـات التعليميـة عـن طريـق الصفوف الافتر اضية”.

r. “'المساعدة على نشر التقنية في المجتمع وإعطاء مفهوم أوسع للتعليم المستمر '." r. ““تقيم الخدمات المساندة في العملية التعليمية مثل التسجيل المبكر و إدارة الصفوف الدر اسية وبنـاء الجداول الدراسية وتوزيعها على المعلمين و أنظمة الاختبار ات و التقييم وتوجيه المتعلم من خلال بوابات الإنترنت". ؛. ؛،إعداد جيل من المعلمين والمتعلمين قادر على التعامل مع التقنية ومهار ات العصرو التطور ات الهائلة التي

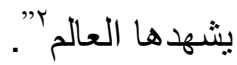
๑. “توفير بيئة تفاعلية غنية ومتعددة المصادر تخدم العملية التعليمية بكافة محاور ها”. 7. “تعزيز العلاقة بين أولباء الأمور و المدرسة وبين المدرسة والبيئة الخارجية”. V. “تطـوير دور المعلـم في العمليـة التعليميـة حتى يتو اكب مـع التطـور ات العلميـة والتكنولوجيـة المسـتمرة و المتلاحقة”. ^. “،دعم عمليـة التفاعل بـين المتعلمـين و المعلمين و المسـاعدين مـن خـلال تبـادل الخبرات التربويـة والآراء و المناقتــات و الحـوارات الهادفة بالاستعانة بقنوات الاتصـال المختلفة مثنل البريد الإلكترونسي وغرف الصف

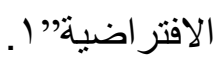

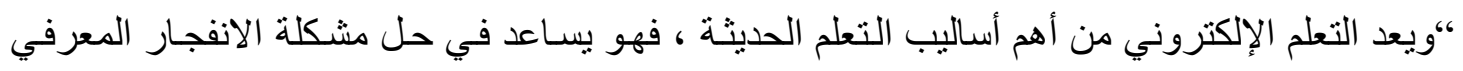
و الطلب المتز ايد على التعليم” ، ““كما يساعد في حل مشكلة ازدحام قاعات المحاضر ات إذا مـا استخدم بطريقة التعلم من بعد، وتوسيع فرص القبول في التعليم” ، “و التمكن من تدريب وتعليم العـلين وتـأهيلهم دون ترك

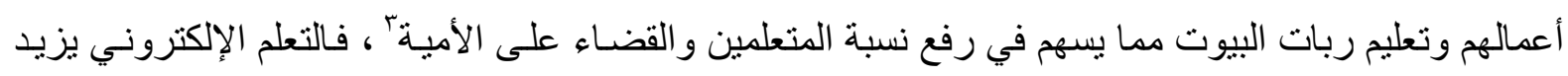
من فعالية التعلم إلى درجة كبيرة ويقلل من ويوفر بيئة؛؛ “، ،“الوقت اللازم للتدريب ويقلل تكلفة التدريب تعلم تفاعليـة ويسـح للمتعلم بالدر اسـة في الوقت والمكـان الذي يفضـله ويتيح عمل مقابلات ومناقتــات حيـة على الثبكة، ويوفر معلومـات حديثة تنسـم مـع احتياجـات المتعلمين، ويـوفر بـرامج المحاكاة والصسور المتحركة

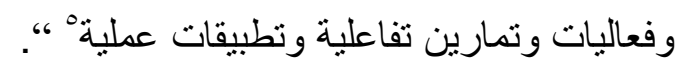

\section{6، كأنواع التعليم الإكتروني" : “، التعليم الإلكتروني يقدم نوعين من التعليم” :}

“ Synchronous E-Learning : كلنوع الأول : التعليم التزامني “و هو التعليم على الهواء الذي يحتـاج إلى وجود المتعلمين في نفس الوقت أمسام أجهزة الكمبيوتر لإجر اء النقاش و المحادثة بين الطلاب أنفسهم و بين المعلم عبر غرف المحادثة أوتلقي الدروس (Chatting)” 
6،النوع الثاني : التعليم غير التزامني: Asynchronous E-Learning "، “،و التعليم غير المباثر الذي لا يحتاج إلى وجود المتعلمين في نفس الوقت أو نفس المكان ، و يتم من خلال بعض تقنيات التعليم الإلكتروني مثل البريد الإلكتروني حيث يتم تبـادل المعلومـات بين الطلاب أنفسـهم و

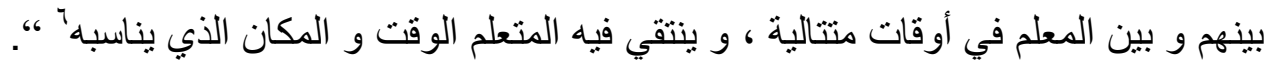

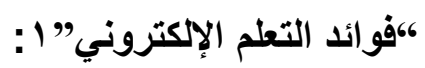

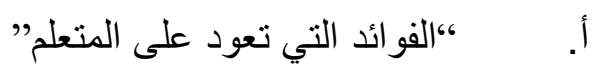

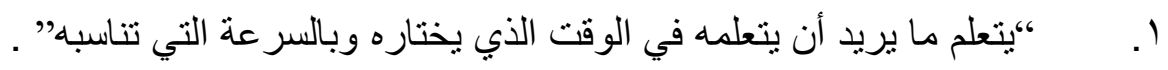

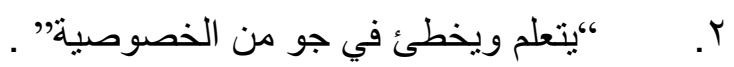

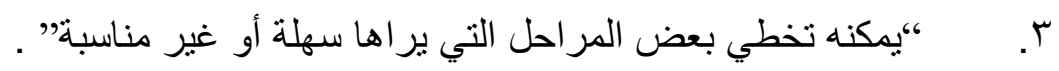
ع. ،يمكنه الإعادة والاستز ادة بالقدر الذي يحتاجه”.

$$
\begin{aligned}
& \text { بـ “،الفوائد التي تعود على المعلم” } \\
& \text { ا - “لا يضطر إلى تكرار الثرح عدة مرات” . } \\
& \text { r “ “يمنح الوقت لإعداد بر امج أكثر”. }
\end{aligned}
$$

rـ ““التركيز على المهارات التي يحتاجها المتعلم فعلاً. ـ ـ “"يركز أكثر على التخذية المرتدة للمتعلم”. هـ “تتاح له فرصة أكبر لتنمية قدرات مختلفة.يجعل كما هائلا من المعلومات في متناول يده'.

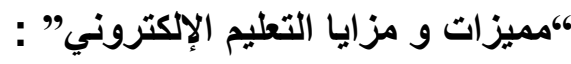

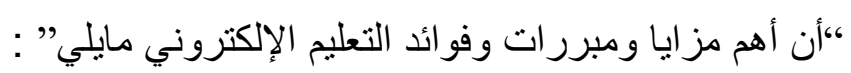
( ) “زيادة إمكانية الاتصال بين الطلبة فيما بينهم ، وبين الطلبة والمدرسة ، وذللك من خلال سهولة الاتصـال مـا بين هذه الأطر اف في عدة اتجاهات مثل مجالس النقاش، البريد الإلكتروني ، غرف الحوار ويرى الباحثين أن هذه الأشياء تزيد وتحفز الطلاب على المشاركة والتفاعل مع المو اضيع المطروحة” ץ) “،المساهمة في وجهات النظر المختلفة للطلاب ، المنتديات الفورية مثل مجالس النقاش وغرف الحوار تتيح

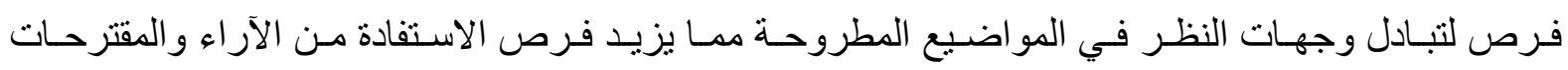
المطروحة ودمجها مـع الآر اء الخاصـة بالطالب ممـا يسـاعد في تكوين أسـاس متنين عند المتعلم وتتكون عنده معرفة وآراء قوية وسديدة وذلك من خلال ما اكتسبه من معارف ومهار ات عن طريق غرف الحوار” . r) “،الإحسـاس بالمسـاواة ، بمـا أن أدوات الاتصـال تتيح لكل طالب فرصـة الإدلاء بر أيسه في أي وقت ودون

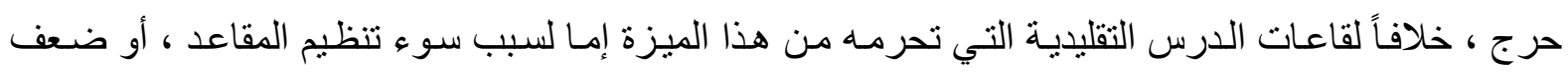
صوت الطالب نفسه ، أو الخجل ، أو غير ها من الأسباب ، لكن هذا النوع من التعليم يتيح الفرصة كاملة للطالب 
لأنه بإمكانه إرسال رأيه وصوته من خلال أدوات الاتصال المتاحة من بريد إلكتروني ومجالس النقاش وغرف الحوار".

ع) “سهولة الوصول إلى المعلم ، أتاح التعليم الإلكتروني سهولة كبيرة في الحصول على المعلم و الوصول إليه في أسرع وقت وذللك خارج أوقات العمل الرسمية ، لأن المتدرب أصبح بمقدوره أن يرسل استفسـار اته للمعلم من خلال البريد الإلكتروني، و هذه الميزة مفيدة وملائمة للمعلم أكثر بدلا من أن بظل مقيداً على مكتبه. وتكون

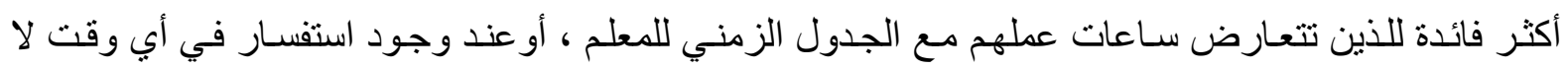
يحتمل التأجيل" .

0) “"إمكانية تحوير طريقة التدريس ، من المككن تلقي المـادة العلميـة بالطريقة التي تتاسب الطالب فمنهم من تناسبه الطريقة المرئية ، ومنهم تتاسبه الطريقة المسموعة أو المقروءة، وبعضهم تتناسب معه الطريقة العملية ، فالتعليم الإلكتروني ومصادره تتيح إمكانية تطبيق المصادر بطرق مختلفة وعديدة تسمح بـالتحوير وفقاً للطريقة الأفضل بالنسبة المتعلم" . 7) “ملائمة مختلف أساليب التعليم ، التعليم الإلكتروني يتيح للمتعلم أن يركز على الأفكار المهـة أثناء كتابته وتجميعه، للمحاضرة أو الدرس، وكذلك يتيح للطلاب الذين يعانون من صعوبة التركيز وتنظيم المهام الاستفادة من المادة وذلك لأنها تكون مرتبة ومنسقة بصورة سهلة وجيدة و العناصر المهمة فيها محددة” .

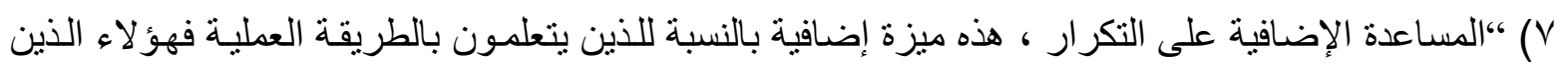
يقومون بالتعليم عن طريق التدريب ، إذا أرادوا أن يعبروا عن أفكار هم فإنهم يضعوها ها في جمل معينـة ممـايعني أنهم أعادو ا تكرار المعلومات التي تدربوا عليها وذللك كما يفعل الطلاب عندما يستعدون لامتحان معين” . ^) “توفر المناهج طوال اليوم وفي كل أيام الأسبوع ( §Y سـاعة في اليوم Vأيام في الأسبوع ) ، هذه الميزة مفيدة للأشخاص المزاجيين أو الذين يرغبون التعليم في وقت معين ، وذلك لأن بعضهم يفضل التعلم صباحاً و الآخر مساءاً ، كذللك للذين يتحملون أعباء ومسئوليات شخصية ، فهذه الميزة تتيح للجميع التعلم في الزمن الذي يناسبهم” .

9)" الاستمر ارية في الوصسول إلى المنـاهج ، هذه الميزة تجعل الطالب في حالـة استقر ار ذلك أن بإمكانسه الحصول على المعلومة التي يريدها في الوقت الذي يناسبه ، فلا يرتبط بأوقات فتح و إغلاق المكتبة ، مدـا يؤدي إلى راحة الطالب و عدم إصابته بالضجر” " . • () “"عدم الإعتمـاد على الحضور الفعلي ، لا بد للطالب من الالتزام بجدول زمني محدد ومقيد وملزم في العمل الجمـاعي بالنسـبة للتعليم التقليدي ، أمـا الآن فلم يعد ذلك ضـرورياً لأن التقنيـة الحديثـة وفرت طـرق

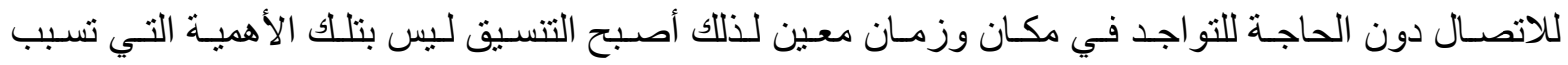

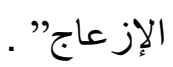
1) (1) بهولة وتعدد طرق تقييم تطور الطالب ، وفرت أدوات التقييم الفوري على إعطاء المعلم طرق متنوعة لبناء ونوزيع وتصنيف المعلومات بصورة سريعة وسهلة للتقييم" . 


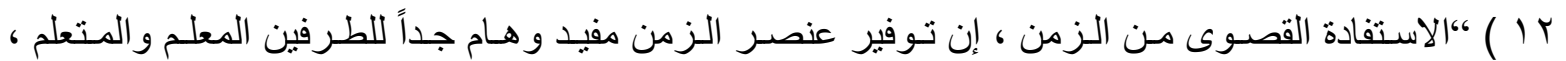
فالطالب لديه إمكانيـة الوصـول الفوري للمعلومـة في المكان و الزمـان المحدد وبالتـالي لا توجد حاجـة للذهاب

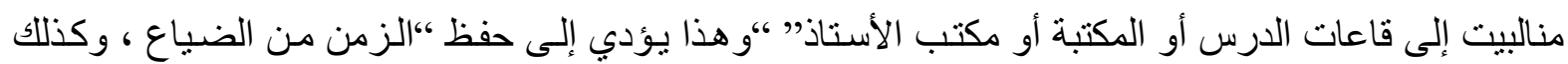
المعلم بإمكانه الإحتفاظ بزمنه من الضياع لأن بإمكانه إرسال ما يحتاجه الطالب عبر خط الاتصال الفوري" . با (1 ) “تقليل الأعباء الإدارية بالنسبة للمعلم ، التعليم الإلكتروني يتيح للمعلم تقليل الأعباء الإداريـة التي كانت تأخذ منه وقت كبير في كل محاضرة مثل استلام الواجبات وغير ها فقد خفف التعليم الإلكتروني من هذه العبء

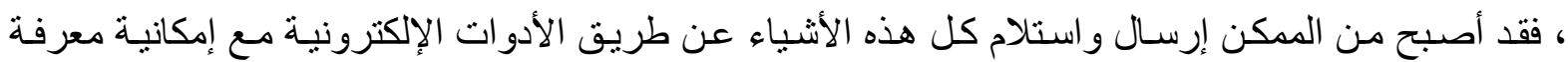
استلام الطالب لهذه المستتدات .

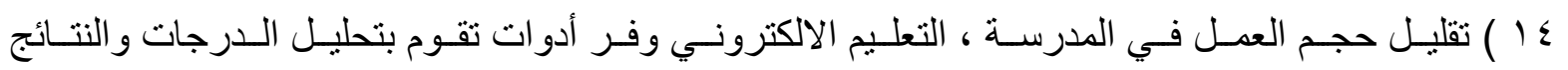
والاختبار ات وكذلك وضع إحصائيات عنها وبمكانها أيضا إرسال ملفات وسجلات الطلاب إلي مسجل الكلية'،

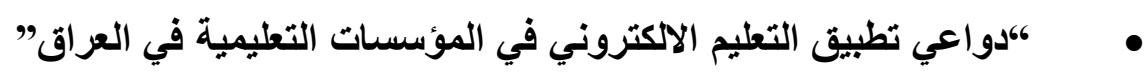
1. "،يوفر بجانب كل كتاب ورقي ومرشد المعلمين منهج إلكتروني”. r. “يضيف بدائل تعليمية تربوية تقنية تفاعلية مع اصرة تسهل عمليتي التعليم والتعلم وتسهم في رفع مستوى

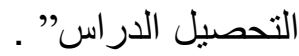
r." يسهم في محو الأمية المعلوماتية لأكبر شرائح المجتمع العراقي” . ع. “،وفر الدعم المنهجي للمشـاريع والخطط الإستر اتيجية التي تتبناهـا الدولة في مجـال تكنولوجيـا المعلومـات والاتصالات ،مثل خطة الحكومة الالكترونية، و البرنامج الوطني لتقنية المعلومات . ه. يمثل مدخلاً فعالاً لتحقيق جودة التعليم ويضمن الارتقاء به" . 7. “"يحقق غايات وأهداف الإستر اتيجية القوميـة الثـاملة للتعليم ، حيث تتطلقبق أهدافه الكتاب الالكتروني مـع أهداف الكتاب الورقي من حيث الإرتباط بفلسفة التعل يم العام .. ويكون الإختلاف في اسلوب عرض المفردات

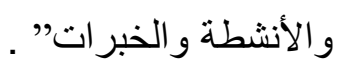

V. “دعم كبير للتعليم المعتاد والمساهمة في تعليم الكبار وغير المتفرغين لحضور صفوف المدارس النظامية” ^. “،التعلم الذاتي: التعلم الذاتى فى أى وقت ومن أى مكان” . 9. “'التفاعل اللغير متز امن فى أى وقت ومن أى مكان” . . • . ."البحث المباشر و الحصول على المواد العلمية ومصادر المعرفة” .

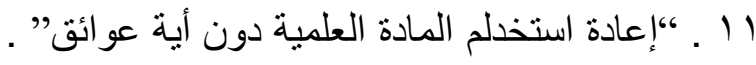

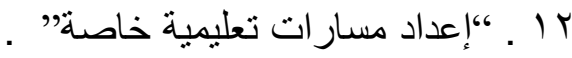
"ا ـ ـالتقويم الذاتى المستمر" .

ع ا "زيادة فرص التعلم. وفي دافعية الطالب نحو التعلم عن طريق اتاحة بيئة تعليمية أكثر تثويقاً و إثارة للإنتباه” 10 ـ ، كاتاحة مجموعة من الأدوات المتقدمة للمعلمين لزيادة فاعلية التعليم”. 7 17 ـ “زيادة فرص الفهم والتطبيق عن طريق الوسائط المتعددة التفاعلية”. 


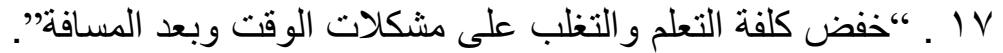
11 . " مكافحة ظاهرة الدروس الخصوصية". .

\section{الاستنتناجـات والتوصسيات}

\section{من خلال ما تقدم يمكن الخروج بالاستنتاجات الآتية:}

ا. “"إن التقدم العلمي و التكنلوجي يفرض نفسه على كافة ميادين الحياة ومنها التعليم العالي الذي هو أسـاس هذا التقدم، لذا يجب مو اكبة هذا التقدم خاصة في بلدنا العراق الذي يعاني من أزمة حادة في التعليم العـالي. ومن بين

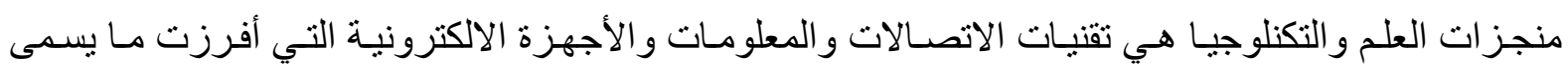
بالتعليم الالكتروني.” r. “"إن مفهوم التعليم الالكتروني يشمل أنماطـا متنوعة، منها التعلم بالحاسوب و وسـائل العرض الالكتروني، و التعلم من خـلال شبكة الانترنت، والتعلم من خـلال شبكة قو اعد البيانـات، و التعلم بتوظيف شبكة المعلومـات والاتصالات، و التعلم في بيئة افتر اضية، وتوظيف تقنية التعلم عن بعد”. T. “،إن معظم الدر اسات التي أجريت على مخرجات التعليم الالكتروني تؤكد على فاعلية هذا النوع من التعليم في تطوير كفاءة الطلبة والتدريسبين على حد السواء، ولذا سـار عت الكثير من الدول لإدخال تجربـة التعليم

$$
\text { الالكتروني في جامعاتها ومدارسها’. }
$$

V. ،“للتعليم الالكتروني ميزات وايجابيات عديدة منها؛ اختصار الوقت وتقليل الجهد المبذول في التدريس، جعل التعليم أكثر تثويقاو وتعة، تعليم عدد كبير من الطلاب دون قيود الزمان والمكان، تحفيز التعليم الذاتي، إمكانيـة استع ا رض كم كبير من المعلومـات”، “سـهولة تحديث المواد التعليميـة المقدمة الكترونيـا بكل مـا هو جديد، و غير ذلك كثير ـ وفي مقابل هذه الايجابيات الكثيرة، فإن هنالك سلبيات وصعوبات في التعليم الالكتروني وهي؛ ضعف للتفاعل الإنساني بين الأستاذ والطالب، و افتقار نسبة كبيرة من التدريسيين و الطلبـة لخبرة التعامل مـع وسائل تكنلوجيا المعلومات والاتصـالات”، و “"عدم توفر مستلزمات التعليم الالكتروني بشكل كاف، و مشكلة

الانقطاع المتكرر للتيار الكهربائي التي تعد عقبة أساسية أمام تطبيق التعليم الالكتروني في جامعاتنا العر اقية.”

$$
\text { “أما التوصيات التي يمكن الخروج بها من هذا البحث فهي:” }
$$

ا. “،رورة اعتماد وسـائل وتقتيات التعليم الالكتروني المتعددة في جامعتنا لمو اكبة التقدم المعرفي و التقني

الهائلين ولتجسير الهوة بين جامعتنا العر اقية والجامعات العالمية”.

r. “توفير الدعم المادي لتوفير مستلزمات وتقنيات التعليم الالكتروني من حواسيب و وسائل عرض الكتروني، وشبكات اتصالات عبر الانترنت، وقو اعد بيانات ومكتبات افتر اضية مع شبكاتها، وقاعات و تأثيث مناسب لهذا النوع من التعليم.”

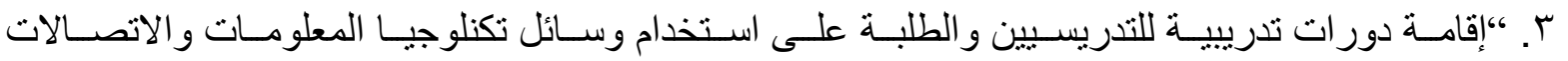


ع. ،“نظر الوجود بعض السلبيات في التعليم الالكترونس، فنوصي أن لا يكون التعليم الالكتروني بديلا عن

التعليم التقليدي، بل مكملا له.."

\section{هوامش البحثث}

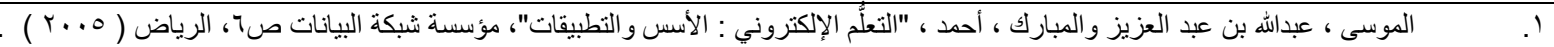

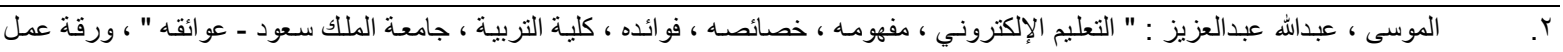

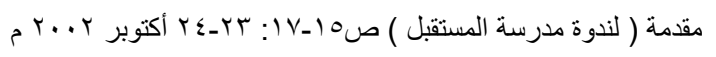

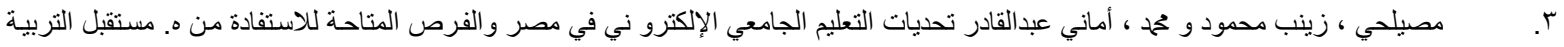

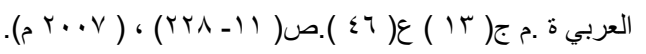

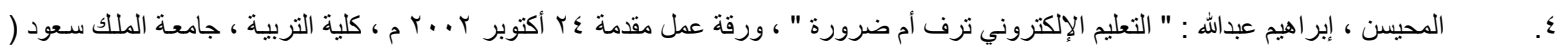

لندوة مدرسة المستقبل ) .

•. المبيريك : هيفاء : " التعليم الإلكتروني : تطوير طريقة المحاضرة في التعليم الجامعي باستخدام التعليم الإكتروني مع نموذج مقترح " صلآ، ورقة

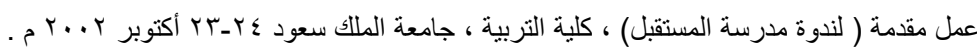

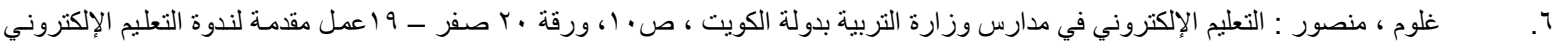

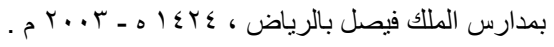

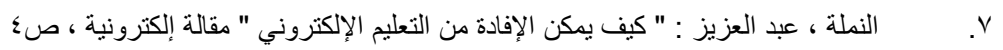

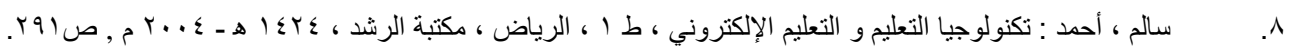

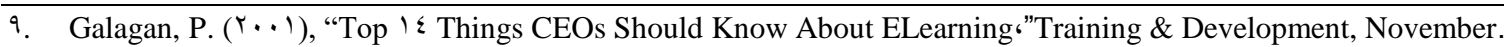
• 1. زيتون ، حسن حسين ، رؤية جديدة في التعليم ـ التعليم الالكتروني ـ المفهوم ، القضايا ، التطبيق ، التقويم ، الرياض ، الدار الصولتية للتربية ،

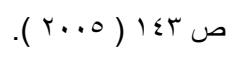

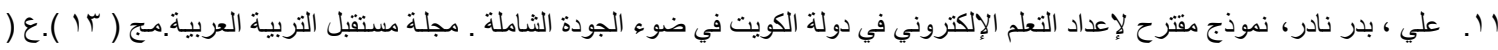

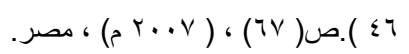

rr. . الصالح، بدر عبداله . المنظور العولمي لتقنية الاتصالات والمعلومات : مدى جاهزية الجامعات السعودية للتغيير. ورقة عمل مق دمة لندوة العولمة

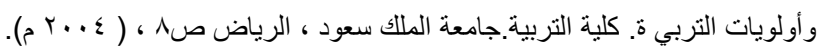

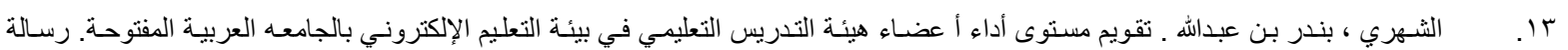

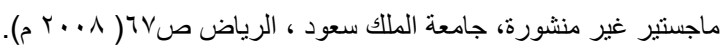

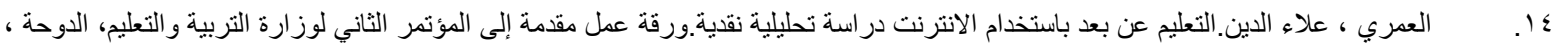

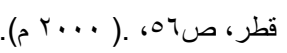

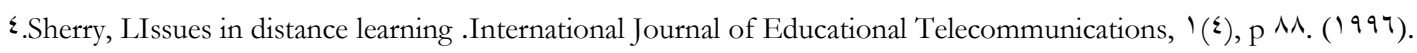

$$
\text { ه. فرج ، علاء الدين. التعليم الإلكتروني كأحد رو افد العطلية التعليمي ة.بحث مقدم للمؤتمر السنوي الثاني لمركز التعليم }
$$

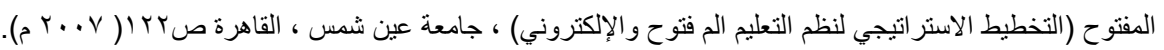

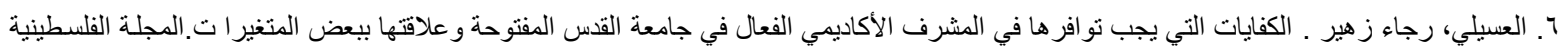

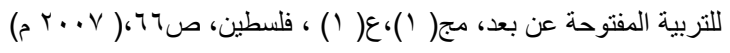

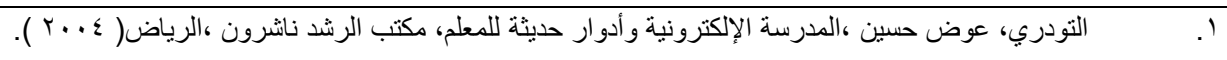

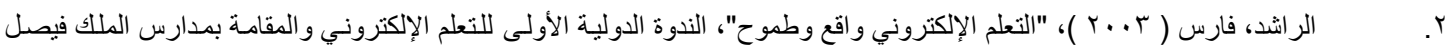

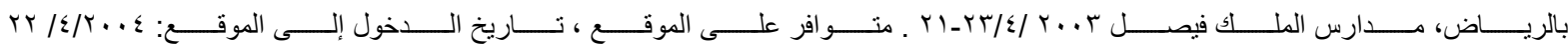
http://www.kfs.sch.sa/ar/sim.htm،

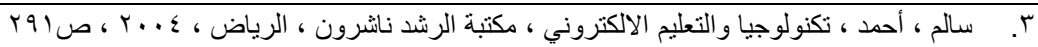

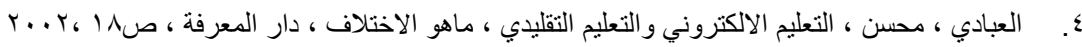

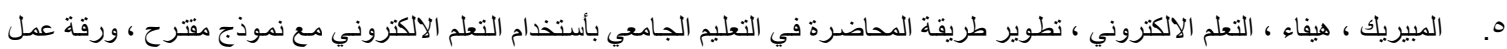

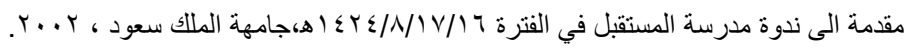

ๆ. Guckel , K. \& Ziemer, Z. (Y..r), "E- learning Seminar: The Training of Cross -Cultural Competence and Skills", Univeratiy Hlidesheim. Retrieved, March rr, r. . $\varepsilon$. from: http://www.unihildesheim. de/beneke/WS • I • r/meth/An 


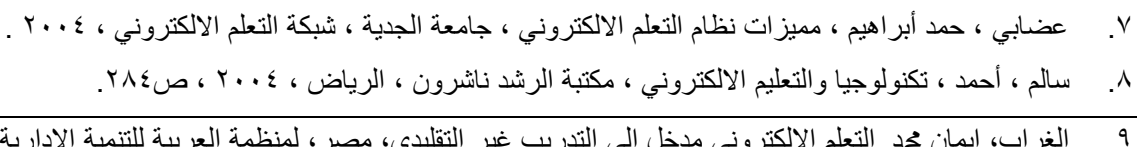

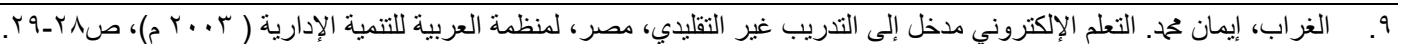

1. Race, P., (1991), “0. Tips for open and flexible learning”, Kogan Page Limited, London N I 9JN, UK.

الموسى ، عبداله عبدالعزيز : " التعليم الإكتروني ، مفهومه ، خصائصهه ، فو ائده ، كلية التربية ، جامعة الملك سعود - عو ائقه " ، ورقة عمل مقدمة (لندوة

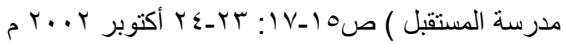

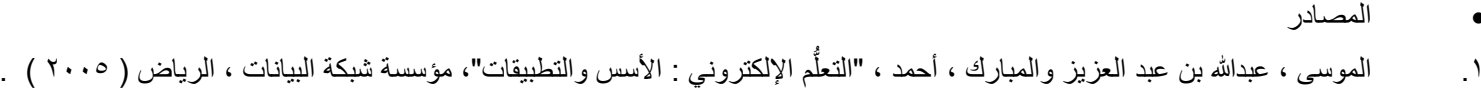

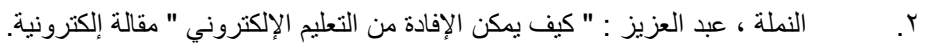

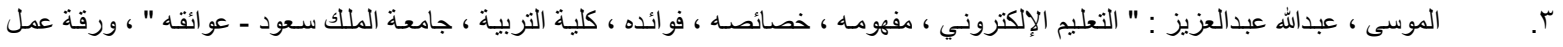

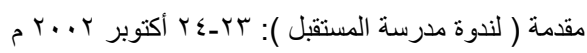

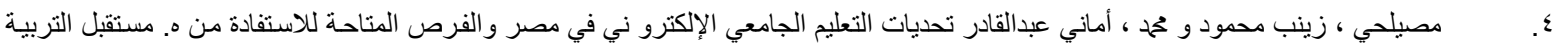

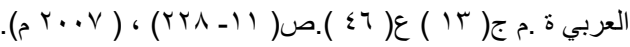

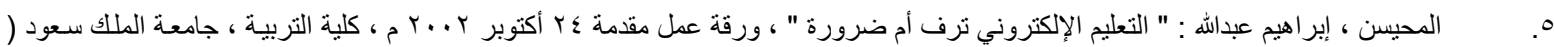
لأندوة مدرسة المستقبل ) .

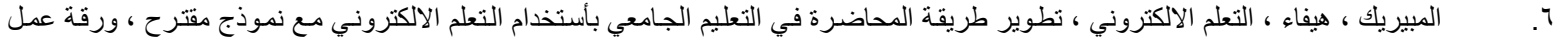

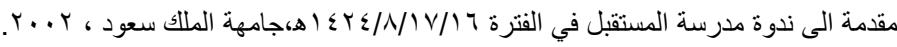

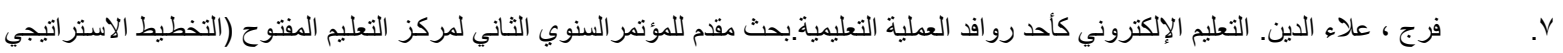

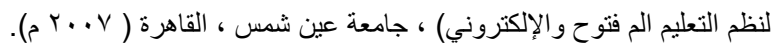

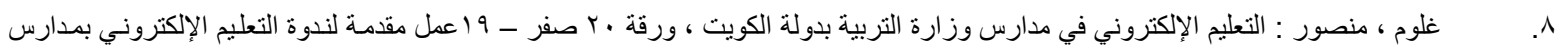

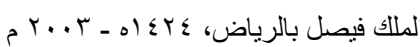

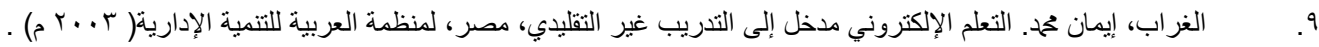

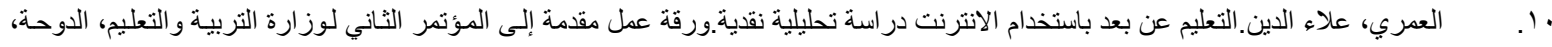

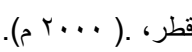

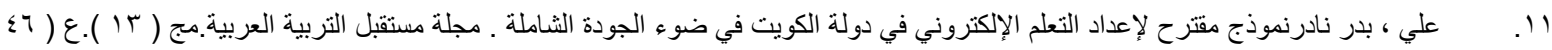
( ) (

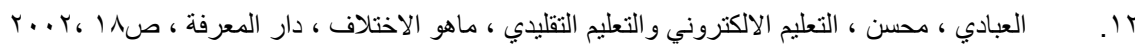

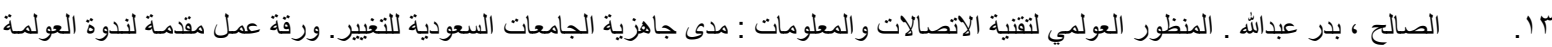

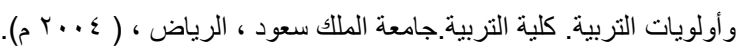

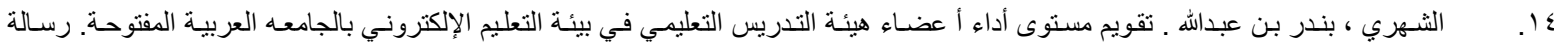

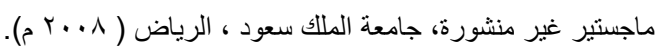

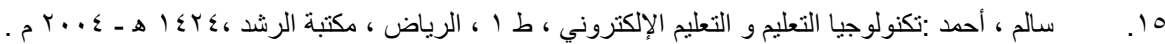

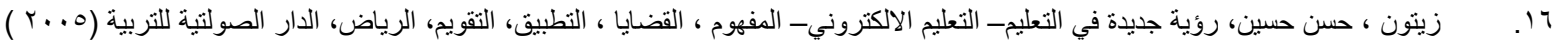

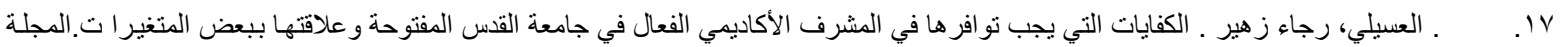

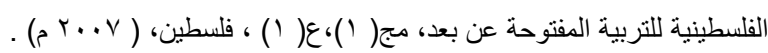

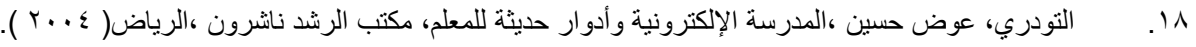

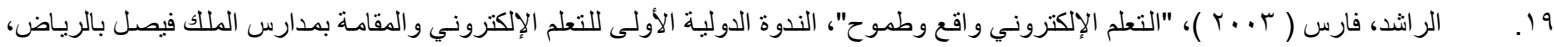

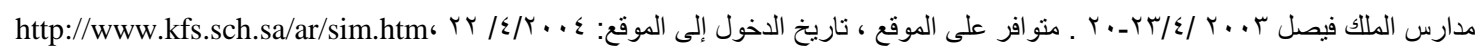

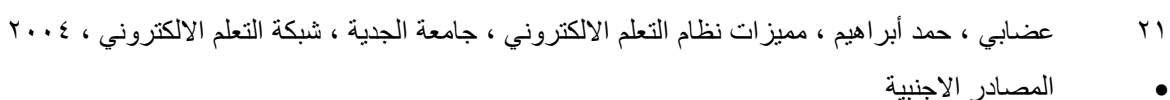

1- Galagan, P. ( $(\cdots)$ ), “Top I \& Things CEOs Should Know About ELearning”, Training \& Development, November.

r. $\quad$.Sherry, LIssues in distance learning .International Journal of Educational Telecommunications, ( (₹), ( ( 99 ४).

r- $\quad$ Guckel, K. \& Ziemer, Z. ( $\uparrow . . r)$, "E- learning Seminar: The Training of Cross -Cultural Competence and Skills", Univeratiy Hlidesheim. Retrieved, March $r$ r, ${ }^{\prime} \ldots \varepsilon$. from: http://www.unihildesheim. de/beneke/WS • ${ }_{-} \cdot r / m e t h / A n$

$\varepsilon-$ Race, P., (।99^), “० . Tips for open and flexible learning”, Kogan Page Limited, London N I 9JN, UK. 